\title{
Farmers' Attitude and Factors Influencing The Adoption of Artificial Insemination in Goat Farming System
}

\author{
Julian Witjaksono ${ }^{1, *}$, Dahya $^{1}$, Edi Tando ${ }^{1}$, Entis Sutisna ${ }^{1}$, Jemmy Rinaldi $^{2}$ \\ ${ }^{1}$ The Assessment Institute for Agricultural Technology of Southeast Sulawesi. Kendari. 93114. \\ Indonesia. \\ ${ }^{2}$ The Assessment Institute for Agricultural Technology. Bali. Indonesia.
}

\begin{abstract}
Small Ruminant such goats are familiar to keep growing for a farming system in the rural area. However, farmers are facing many problems to grow them. This study describes the goat farming system's performance in the rural area based on the farmers' attitude and factors influencing farmers in adopting Artificial Insemination of the goat farming system. This study was conducted in Wunduwatu Village Andoolo Sub District, South Konawe District of Southeast Sulawesi Province in 2015. The research method was employed based on the survey and interview using a questionnaire through a purposive sampling method for selecting respondents that have chosen 30 farmers. Research findings show that its farming system's performance indicated the traditional pattern such as feed performance and farm management. It is due to the lack of skill and lack of capital. Most of the respondent farmers (44.29\%) perceived artificial insemination is a good program. Moreover, $60.50 \%$ of respondents stated that using artificial insemination is better than using a male / natural mating.
\end{abstract}

\section{Introduction}

The Goat farm system has played an important role in increasing meat production, as the source of family income, and generating employment opportunities. Public interest in developing goat livestock continues to increase based on the consideration that small ruminants have advantages, including developing and surviving in all agroecological zones.

The development of goat farming system today are facing many problems, including a) extensive pattern of raising goat, b) low daily weight, c) the management of feeding has not been adjusted to the physiological conditions of the small ruminants, and d) the types of local breeder developed by the community still dominated by Kacang goats and a small portion cultivating the 'Peranakan Etawah' (PE) goats breeding [1]. One of the efforts that can be made to increase the production and productivity of goats in Southeast Sulawesi is to increase genetic quality diversity. The addition of genetic diversity is technically expected

\footnotetext{
*Corresponding author: julian_witjaksono@yahoo.com
} 
to affect the formation of new genetics that have certain advantages over existing genetics [2].

Boer goat is a type of meat goat that has a great opportunity to be developed in Southeast Sulawesi because it is classified as a tropical goat that can adapt to various environmental conditions, can live in scrub areas, rocky mountain slopes, or in grasslands. This goat for males' adult weight reaches $110 \mathrm{~kg}$ and for females is $100 \mathrm{~kg}$ [3] with the growth rate reaches more than $225 \mathrm{gr} /$ head/day [4]. Genetic improvement is the one strategy to increase goat growth. The results of [3] show that there is a significant increase in the growth of Boerawa goats (Boer goats x PE goats) and Boercang goats (Boer goats $\mathrm{X}$ Kacang goats) compared to PE goats and Kacang goats under people's care conditions. Besides, the mortality rate for pre-weaning cross-bred goats is lower than the mortality rate for pre-weaning Kacang goats [5]. According to [6], improving the quality of Kacang goats or PE goats can be done by crossbreeding with Boer goats particularly through artificial insemination.

Artificial Insemination Technology using Boer goat semen accompanied by the application of management of artificial insemination results and handling of recipient broodstock can increase diversity and improve the genetic quality of local goats and economically increase household income. This study aimed to know the farmers' attitude toward introducing artificial insemmination in the goat farming system and finding factors influencing farmers' decision to adopt Artificial Insemination.

\section{Methods}

The study activity on the adoption of Artificial Insemination technology innovation in goats was carried out from January 2015 - December 2015. The location of the study was conducted in Wunduwatu Village, Andoolo Sub District, South Konawe Regency. The selection of sample villages was based on considering that these locations were chosen to develop the goat AI program implemented by the local government of South Konawe Regency.

The data collected is based on the surveys and interviews using questionnaires with 30 cooperator farmer respondents. The respondents' selection used purposive sampling method as cooperator farmers; the local breeders involved in the AI program. Surveys and interviews are determined farmers' attitudes and factors influencing farmers to adopt AI.

Data analysis employed a descriptive analysis based on the farmers' attitudes and factors influencing farmers' decision to adopt Artificial Insemination. Variables of farmers' attitudes are knowledge of AI, encouragement, adjustment, and perception. Furthermore, factors influencing farmers to adopt this technology are profitable, easily implemented, trialability, adjusting, and observable.

\section{Results and discussion}

\subsection{Goat farming system}

\subsubsection{Farm Management}

The goat farm management system applied in cooperator farmers is an intensive system, where livestock are kept all day long in pens. The right rearing system can increase goats' productivity, as stated by [1] [3]. Two main factors for the low productivity of goats are genetic ability to grow and low maintenance management due to long calving distances [8]. 
An intensive system's advantage is that farmers can routinely pay attention to their livestock, such as; 1) cleaning cages, 2) collecting manure, and 3) providing forage feed, supplementary feed, and drinking water. In addition, incidental treatment includes: 1) cutting goat's nails, 2) castration or castration, 3) health checks and administration of drugs, 4) giving identification, 5) cutting horns, and 6) vaccination [9]. Several aspects of maintenance management applied in this study include housing, feed, and health management.

\subsubsection{Housing}

A pen is a place for livestock to spend their time. Besides, the pen serves to protect livestock from hot sun, rain, wind, disease and to save labor and time, and maintenance. Therefore, good and strong cage construction can guarantee high productivity [10]. The cage model applied by cooperators is the majority of stage cages with various sizes according to the number of raised livestock. This cage has advantages, including facilitating cage sanitation, smooth air circulation, and safe from other animal disturbances.

Farmers have implemented a baffle system in pens, but the livestock grouping for each section is only based on the sex and the cattle age. This grouping is not based on livestock's physiological status, such as pregnant goat, lactating, heifers. Moreover, this factor is thought to cause a miscarriage or a child dying before birth. This condition usually results in a collision in the pregnant mother's stomach by another goat in one cage, especially during feeding. The bulkhead size is also not based on the livestock's optimal needs, so that sometimes the number of livestock in one segment is too dense.

The study activity, especially cooperator farmers, repair their pens based on the optimum size according to livestock's recommended standards. The goat placement in each cage partition is based on the goat's physiological status, especially for pregnant and lactating goats.

\subsubsection{Feed}

Goats are a type of ruminant that prefers to eat various forages instead of pure grazers. Breeders use forage as the main feed given to goats. Meanwhile, additional feed such as bran or tofu dregs has never been tried. The types of forage provided by the majority come from legumes such as gamal, lamtoro, and calliandra. Besides, it also comes from other woody plants such as waru leaves, jackfruit leaves, and leaves of agricultural waste [11].

The feeding system is cut and carry pattern and is given ad libitum regardless of each animal's number of needs. Giving is done in groups to allow competition for feed. Heavier or bigger livestock have more opportunities to get feed. During the rainy season, where there is a surplus of forage, it is easier for farmers to get forage. One feed intake only takes \pm 0.5 hours to fulfill 5-6 goats. Meanwhile, in the dry season, it takes \pm 1 hour. Forage is given twice a day in the morning and evening.

\subsection{Farmers' Attitudes of Introducing Goats Artificial Insemination}

Constrains in the field related to the deployment of artificial insemination technology came from the service system's weaknesses, human resources for artificial insemination officers (inseminators), human resources for breeders, and difficulty in reaching remote areas [12]. Apart from some of these weaknesses, the most important thing is accepting the technology itself by breeders. Farmer acceptance of innovation is related to their perception of innovation. In contrast, farmers perceive themselves as related to their respective breeders' background because acceptance of innovation will be influenced by the breeders' 
perceptions and characteristics [7]. The communities of Wunduwatu villages, although they are relatively homogeneous communities as agricultural societies, individually have different characteristics, thus, the perceptions and acceptance of farmers will also be different from one to another. The variables observed in this study were farmers 'perceptions of artificial insemination innovations, which were measured through subvariables: (1) farmers' knowledge level regarding artificial insemination; (2) farmers' interest in artificial insemination; (3) farmer assessment of artificial insemination.

Farmers' perceptions of Artificial Insemination are the responses of goat breeders to Artificial Insemination, which can be seen from the breeders' level of knowledge, interest of breeders, and beef cattle farmers' assessment of the benefits of artificial insemination as an innovation for them [13].

Tabel 1. Farmers' Attitude of Introducing Goat Artificial Insemination

\begin{tabular}{|l|l|c|c|c|}
\hline \multirow{2}{*}{ No. Justification } & \multicolumn{3}{|c|}{ Indicators } \\
\cline { 3 - 5 } & & High & Medium & Low \\
\cline { 3 - 5 } & & $-----\cdot--\cdot \%$ & 20.50 \\
\hline 1. & Knowledge of AI & 31.50 & 42.00 & 26.30 \\
\hline 2. & Encourage & 50.50 & 12.50 & 22.26 \\
\hline 3. & Adjusted & 52.87 & 10.87 & 23.92 \\
\hline 4. & Perception & 44.29 & 21.79 & \\
\hline
\end{tabular}

Sumber : Primary Data Tabulated

Table 1 shows that most of the respondents (44.29\%) perceived artificial insemination is a good program. The breeders' knowledge is quite good because the study location (Wunduwatu) is the breeders' development area. Interests breeders against AI, which are classified as good (50.50\%) because breeders have seen the success of AI cows. Therefore, they want to try and see the results of AI goats. However, they have concerns that if AI mated with semen from a large goat type, it will give birth to a large calf (fetus), which causes the female goat to be challenging to give birth and has a risk of death [14].

\subsubsection{Factors influencing farmers decision to Adopt Artificial Insemination innovation}

The stages of a person's decision to accept or adopt an innovation generally go through five stages, namely: awareness, interest, assessment, try and accept [13]. Furthermore, [15] stated that artificial insemination as innovation is a stimulus for farmers to respond based on the innovation itself, which has the following properties: relative advantage, conformity to circumstances (compatibility), difficulty level (complexity), can be tried on a small scale (triability), and the results can be seen (observability). For more details, see table 2 below.

Table 2. Factors influencing farmers decision adopting goat's Artificial Insemination innovation

\begin{tabular}{|c|c|c|c|c|}
\hline \multirow{3}{*}{ No. } & \multirow{3}{*}{ Justification } & \multicolumn{3}{|c|}{ Indicators $(\mathrm{n}=\mathbf{3 0})$} \\
\hline & & High & Medium & Low \\
\hline & & \multicolumn{3}{|c|}{ - } \\
\hline 1. & Profitable & 50.87 & 5.13 & 30.00 \\
\hline 2. & Compatability & 60.50 & 7.20 & 20.50 \\
\hline 3. & Easily Implemented & 29.00 & 21.75 & 37.25 \\
\hline 4. & Triability & 71.50 & 6.70 & 11.50 \\
\hline 5. & Observability & 70.50 & 2.26 & 18.00 \\
\hline 6. & Adjusting & 52.87 & 10.87 & 24.26 \\
\hline
\end{tabular}

Source : Primary Data Tabulated 
Table 2 shows that the respondent breeders (cooperator breeders) rated artificial insemination as good as $50.87 \%$. Farmers' good assessment of artificial insemination's relative benefits is because breeders have seen the results of AI cattle [14] from cooperator breeders who have rapid weight gain. It is in line with [3] that by using artificial insemination, breeders get superior seeds. [11] also argues that using artificial insemination can increase breeding efficiency because only semen with high fertility is given to farmers. The calving interval can be shortened and the number of females that mate repeatedly can be reduced.

Compatability is the extent to which artificial insemination innovation is consistent with breeders' needs (innovation recipients). Most of the respondents $(60.50 \%)$ stated that using artificial insemination is better than using a male / natural mating. However, a small proportion was worried about the mother's risk of death during childbirth because the child born was relatively bigger [16]. In terms of the complexity or level of complexity of using AI, most respondents $(37.25 \%)$ considered that it is complicated. This is due to technical constraints in the form of a lack of breeders' knowledge of the libidinous cycle and detecting animal lustful. In implementing artificial insemination, non-technical constraints are the long distance between the breeder and the inseminator's residence. Hence it is costly and needs some time to reach them.

The assessment of most respondents $(71.50 \%)$ is in the good category of triability (can be tried on a small scale) artificial insemination. It is because the farmer can try one or two times AI on his small ruminant, and if it usually fails, the inseminator reduces costs or makes it free for the next AI or breeders to return to using males. The observability value is $70.50 \%$ for the good category because breeders have seen that the cattle produced by AI have higher body weight and are believed to be superior seeds with good quality so that they are expected to have a higher value [12].

\section{Conclusion}

The characteristics of local breeders (farmers) in study locations indicate that the goat farming system that has been developed is a semi-intensive model. With the characteristics of the goats being caged every day, forage is local forage with the cut and carry feeding model. Overall, the measurement of farmers' attitude towards AI shows that farmers' perceptions of AI activities in the study location are in the good category (44.29\%), quite good $(21.79 \%$ ), and the remaining $24.26 \%$ in the poor category. Moreover, factors influencing farmers' decision in adopting this technology based on advantage, compatibility, ease of application of IB, triability, and observability showed a good percentage $(52.87 \%)$, quite good $(10.87 \%)$, and less good $(24.26 \%)$.

\section{References}

1. E. M. Jerret, J. M. Layton, M. D. Pertinez, Y. Mena Sust 12, 3 (2020)

2. T.A. Gypson, As. Aus. J. Ani. Sci 32, 8 (2019)

3. A. R. S Putra, R. Agunga Sustainable Livestock Production in the Perspective of Food Security, Policy, Genetic Resources and Climate Change. (2015)

4. C. Oget, B. Servin, I. Palhiere Ani. Gen. 2019. 50, 1 (2019)

5. Khalil, A. Bachtiar, Evitayani, Trop. Ani. Sci. J. 42, 3 (2019)

6. S. M. Maylinda, O. L. Sarah, W. Busono Ind. J. Ani. Res. 52, 8 (2018)

7. M. Gunaseelan, B. P. Singh, M. R. Verma, K. Pachaiyappan Inter. J. Cur. Micro. App. Sci. 7, 5 (2018) 
8. S. Eiliser, S. Sumadi, G. S. Budisatria, S. Subandrio J. Trop. Ani. Agri. 37,3 (2012)

9. R. Adiwinarti, I. Gede, Budisastria, Rusman, E. Indarto As. J. Ani. Sci. 10, 4 (2016)

10. M. B. Paly Inter. J. Sci. Tech. Res. 7, 9(2018)

11. O. L. Sarah, W. Busono, M. Nasich Inter. J. Med. H. F. Sci. 1, 1 (2017)

12. Y. Kebebew, T. Bekele Inter. J. Adv. Res. Bio. Sci. 5, 7 (2018)

13. A. Berhe, G. Muluken, J. Yousuf J. Dev. Agri. Econ. 12, 2 (2019).

14. A. K. Thiruvenkadan, R. Rajendran Improving Tropical Animal Production for Food Security. (2015)

15. M. Awais, N. Khan Inter. J. Agri. Env. Bio. 7, 2 (2019)

16. M. A. Quddus Bang. J. Anim. Sci. 41, 2 (2012) 